Artigo recebido em 22/07/2014

Aprovado em $30 / 03 / 2015$

Douglas Junio

Fernandes Assumpção Universidade Tuiuti do Paraná (UTP) - e-mail: rp.douglas@ hotmail.com

Doutorando em Comunicação e Linguagens pela Universidade Tuiuti do Paraná (UTP); Mestre em Comunicação, Linguagens e Cultura pela Universidade da Amazônia (Unama) e Bacharel em Comunicação Social: Habilitação em Multimídia e Relações Públicas pelo Instituto de Estudos Superiores da Amazônia (Iesam)

Analaura Corradi Universidade da Amazônia (Unama)-e-mail: corradi7@ gmail.com

Doutora em Ciências Agrárias na área de Agroecossistemas da Amazônia - UFRA/

PA, jornalista, professora / pesquisadora titular da Universidade da Amazônia - Unama/ Coordenadora do Mestrado em Comunicação, Linguagens e Cultura

Fernanda Vasconcelos Brado de Araújo

Universidade da Amazônia (Unama) - e-mail: fernandavbrabo@gmail.com Bacharel em Comunicação Social: Habilitação em Jornalismo pela Universidade da Amazônia - Unama

\section{Amazônia no The New York Times em 2012}

\section{Douglas Junio Fernandes Assumpção, Analaura Corradi e Fernanda Vasconcelos Brado de Araújo}

\begin{abstract}
Resumo
Este artigo tem o objetivo de analisar oito reportagens sobre a região amazônica publicadas no site do jornal The New York Times no ano de 2012, escritas pelo correspondente no Brasil, Simon Romero. A partir de um estudo de caso e de uma análise de conteúdo, busca-se compreender de que forma os assuntos sobre a região são expostos internacionalmente e quais são os valores-notícia adotados pelo periódico em sua veiculação.
\end{abstract}

\section{Palavras-chaves}

Amazônia, The New York Times, Simon Romero, Jornalismo Internacional, Valor-notícia.

\begin{abstract}
This article aims to analyze eight reports on the Amazon published in The New York Times website in 2012, written by its correspondent in Brazil, Simon Romero. From a case study and content analysis, we seek to understand how the subjects over the region are exhibited internationally and what are the values adopted by news-journal in its placement.
\end{abstract}

\section{Keywords:}

Amazon, The New York Times, Simon Romero, International Journalism, News Value. 


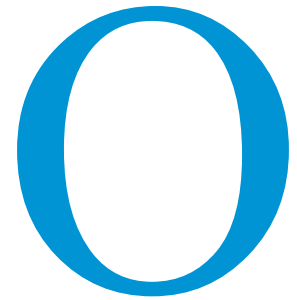

jornalismo nasceu, na modalidade internacional, "com o formato de coleta e difusão de notícias por terras distantes" (NATALI, 2004, p. 22) e teve sua origem no mercantilismo, com o aparecimento de algumas folhas de notícias impressas que eram vendidas a todos. Esta fase é descrita como a Pré-História do Jornalismo, segundo a classificação dos quatro tipos de jornalismo de Ciro Marcondes Filho (2002) em seu livro A Saga dos Cães Perdidos. Entre o período de 1631 a 1789, a imprensa era caracterizada pelo seu modelo artesanal e os jornais eram semelhantes ao livro, mas com poucas páginas. Além disso, ela possuía um conteúdo voltado para o espetáculo, notícias de desastres, mortes de imperadores etc.

No século XIX, tanto o jornalismo internacional como a história econômica passaram por grandes inovações. Em 1814 surgiu a impressão a vapor, em 1865 a impressão rotativa e em 1889 a impressão com a linotipo, que funde todas as letras de uma linha de texto em uma única matriz metálica. Outra revolução tecnológica, durante a segunda metade do século, foi a implementação dos trens e cabos elétricos em várias direções.

$\mathrm{O}$ jornalismo se estruturou como empresa no final do século XIX e então se estabelecia como imprensa de massa, caracterizada pelo período do Segundo Jornalismo. De acordo com Natali (2004, p. 30), a Guerra Civil norte-americana (1861-1865) foi acompanhada por 150 correspondentes de guerra, o que implicou altos custos jornalísticos. Procurou-se a seguir obter informações para divulgação na imprensa por um preço menor. Houve a ideia de formar pools, em que um mesmo repórter ou uma equipe de repórteres produziriam material para muitos órgãos de imprensa.

Logo, criou-se a primeira agência de notícias, em 1835, na França. A agência Havas, criada por Charles Havas, tinha a função de traduzir as informações publicadas por outros jornais europeus, para o uso dos periódicos franceses. Com o tempo, passou a produzir informações com uma equipe de reportagem. "As agências deram viabilidade econômica ao noticiário internacional. Um texto distribuído a centenas de jornais que assinam os serviços de uma agência sai incomparavelmente mais barato que um texto produzido por correspondentes ou enviado especial" (NATALI, 2004, p. 31).

\section{O Jornalismo internacional: expectativa no Brasil}

No Brasil, de acordo com Romancini e Lago (2007), a imprensa e o jornalismo surgem 14 anos antes da nossa separação política de Portugal. Assim, a impressão tipográfica no país dependeu da chegada da Corte Portuguesa ao Brasil, em 1808, para fugir da invasão napoleônica na Europa. Com a chegada do príncipe regente, D. João, ao país, houve a criação da Imprensa Régia, que foi instalada no Rio de Janeiro e mantinha uma linha de censura - não imprimia nada "contra a religião, o governo e os bons costumes".

A publicação considerada pioneira na atividade jornalística no país foi o Correio Braziliense ou Armazém Literário, editado por Hipólito José da Costa, desde junho de 1808, em Londres, cidade onde o jornal era impresso e não era submetido à censura. $\mathrm{O}$ Correio era direcionado ao público luso-brasileiro.

Já o primeiro jornal a ser impresso pela 
Imprensa Régia foi o Gazeta do Rio de Janeiro. O periódico, apesar de não ser declarado oficial, era pouco voltado à crítica social. O Gazeta é identificado como um jornalismo próximo ao poder. "Em sentido mais pejorativo, bajulador e subserviente, 'chapa branca"” (ROMANCINI; LAGO, 2007, p. 22).

É só entre o período de 1822 e a maioridade de D. Pedro II, em 1824, que vigorou no país jornais chamados "pasquins". Assuntos nacionais como a separação do Brasil de Portugal, crises do Primeiro Reinado, a regência, conflito entre partidários e adversários eram temas que preenchiam esse tipo de periódico. Segundo Natali (2004, p. 37), há duas razões para que o noticiário no exterior estivesse ausente nos primórdios do jornalismo brasileiro. "Há motivos técnicos (...), as notícias chegavam por navio e as travessias do Atlântico eram demoradas. (...) Em seguida o fato das oligarquias nacionais serem bilíngues", o que dificultava o acesso às informações estrangeiras.

As notícias internacionais começam a chegar ao território com mais frequência com a instalação de um cabo estendido no leito do Atlântico que conectava por telégrafo o Brasil à Europa, em 1874. Três anos depois, a agência Reuter-Havas (que reunia a Reuters e a France Press) abre uma sucursal no Rio de Janeiro. Em agosto do mesmo ano, o Jornal do Comércio trazia impressas notícias internacionais que o Brasil publicava junto com os jornais europeus.

Neste cenário, o jornalismo também passou por modificações. As notícias internacionais começaram a ganhar mais destaques nos noticiários brasileiros no final dos anos 1990 com as tensões internacionais oriundas do fim da Guerra Fria.
“A forma de 'leitura' das pequenas guerras também mudou. Não era mais preciso identificar quais eram os aliados dos Estados Unidos ou os aliados da hoje extinta União Soviética" (NATALI, 2004, p. 51). Com o fim da bipolarização o noticiário passou a lidar com a superpotência norte-americana.

A partir desta nova ordem mundial foi criado um projeto da Organização das Nações Unidas para a Educação, a Ciência e a Cultura (UNESCO), intitulado de Relatório MacBridge, que tinha o objetivo de analisar os problemas comunicacionais mundiais em relação à massa e à imprensa internacional. O nome foi cunhado em homenagem ao político irlandês Sean MacBridge. Neste documento foram verificados vários problemas, entre eles a concentração da mídia, desequilíbrio entre informações de países desenvolvidos e subdesenvolvidos, bem como a comercialização de informações. Então, foi proposta uma democratização da comunicação, fortalecimento das mídias nacionais, para evitar a dependência de fontes externas. No entanto, o relatório foi criticado pelos Estados Unidos e o Reino Unido, que alegaram um ataque à liberdade de imprensa.

Vários processos mundiais reconfiguraram um novo jornalismo internacional, saindo das editorias específicas para assuntos tratados no exterior. Segundo Carlos Marcos Avighi (2007, online) ${ }^{1}$ :

O jornalismo internacional transcende a editoria que lhe tem sido destinada e alcança as demais editorias, o que vale dizer que no panorama mundial definido, os temas internacionais são de tal porte e complexidade
${ }^{1}$ Disponível em $<$ HTTP://www.eca. usp.br/caligrana/n_9/ pdf/02_avighi.pdf >. Acesso em 20 jun 2013. 
que uma editoria exclusiva não poderá dar conta deles.

De acordo com Avighi (2007), tradicionalmente entendia-se que o jornalismo internacional restringia-se às editoriais, porém, pesquisas feitas por ele com alguns alunos de graduação de jornalismo mostraram que as editorias internacionais sofreram modificações e o espaço destinado aos conteúdos internacionais não suportam apenas uma editoria. A alta variedade de assuntos e a cobertura de eventos mundiais direcionam os conteúdos para diferentes setores como a economia, o esporte, a cultura, etc.

Logo, as transformações sociais refletem na comunicação e na cultura. As mudanças alteram a vida da sociedade, bem como o perfil da tecnologia, a organização do trabalho e o uso do tempo livre, conforme se percebe abaixo:

A mídia globalizada apaga a diferença entre "dados estratégicos" (dados científicos, tecnológicos, financeiros, indispensáveis para a globalização) e as informações "de conteúdo" (os "bens culturais", os "produtos comunicacionais", filmes, programas de televisão e outros) (AVIGHI, 2007, online).

De acordo com o jornalista Mateus Netzel (2013), em seu artigo "Editor acre-

${ }^{2}$ Disponivel em $<$ http://observatoriodaimprensa. com.br/news/view/_ ed768_editor_acre-

dita_em_crescimento_do_jornalismo_internacional>.

Acesso em 15 out 2013. dita em crescimento do Jornalismo Internacional", publicado no Observatório da Imprensa ${ }^{2}$, o editor do The New York Times, Arthur Sulzberger Jr., defendeu que o futuro do jornalismo é ser cada vez mais global e digital, visto que as notícias circulam em grande velocidade por todo mundo e a atividade jornalística deveria se voltar para questões internacionais e atingir os variados públicos em diversas partes do mundo.

Um dos argumentos utilizados para ascensão do jornalismo internacional é a importância do Brasil no cenário mundial. Segundo Zanzini (2013, apud NETZEL, 2013, online), editor do caderno Mundo, do jornal Folha de S. Paulo, o papel do país mudou, e logo sua presença na mídia internacional também se modificou. “ O noticiário de política externa hoje tem uma importância maior do que há dez anos", exemplificou. Zanzini destaca que a potência econômica articula-se com a política externa, que reivindica como fato a ser noticiado. "Medidas governamentais nos fazem insubservientes; o Brasil articula os BRICs e começa a despontar como líder efetivo da América Latina, o que incomoda inclusive os EUA; vide o que a Rede Globo tem feito com o assunto Petrobrás na linha da subserviência ao capital estrangeiro, que quer privatização, para lucrar com o produto pré-sal" (Zanzini, 2013, online).

Outra questão levantada pelo artigo é o aumento do interesse da população brasileira sobre a editoria internacional, com o crescimento da renda média dos cidadãos. Em 2012, a Secretaria de Assuntos Estratégicos da Presidência da República divulgou que, no período de 2002 a 2012 , 35 milhões de brasileiros ascenderam à classe média, o que permitiu o aumento da demanda por cursos de idiomas e viagens ao exterior.

Fábio Zanzini (2013, apud NETZEL, 2013, online) argumenta que os principais desafios para equipes de jornalismo internacional estão em superar a cobertura das commodities do noticiário interna- 
cional, já que poucos veículos de comunicação possuem estrutura para realizar coberturas fora de seu país de origem. As informações que chegam das agências aparecem da mesma forma nos mais variados meios. $\mathrm{O}$ uso massivo dessas informações torna homogênea a cobertura do noticiário internacional.

De acordo com Aguiar (2008), as dez maiores agências do mundo em número de clientes e em volume de texto transmitido são a britânica Reuters, as norte-americanas Associated Press (AP) e Bloomberg, a francesa Agence France-Presse (AFP), a espanhola EFE, a italiana Agenzia Nazionale Stampa Associata (ANSA), a alemã Deutsche Presse-Agentur (DPA), a russa Telegrafnoe Agentstvo Sovetskogo Soiuza (ITAR-TASS), a japonesa Kyodo e a chinesa Xinhua.

Segundo Aguiar (2010), as agências de notícias comerciais brasileiras não operam como agências de notícias porque não revendem e não produzem conteúdos exclusivos para os seus clientes. "Grande parte delas sequer destaca pessoal específico para realizar tarefas de apuração, preferindo fazer de cada repórter seu ‘jornal-pai' também (e secundariamente um repórter de agência)" (AGUIAR, 2010, p. 26).

Dentre as agências brasileiras que se mantêm no mercado estão a Agência Brasileira de Notícia, a Agência Nacional e a Agência Brasil, de Brasília, a Lance Press, a Sport Press, a Agência o Globo, do Rio de Janeiro, a Agência Estado, a Folhapress e a Br Press, de São Paulo.

\section{Processo metodológico}

Segundo Martins (2006) o estudo de caso apresenta um recorte de uma situação complexa da vida real. Nesta me- todologia utilizam-se seis formas para coletas de dados: documentos, registros, arquivos, entrevistas, observação participante e artefatos físicos, com procedimentos metodológicos distintos. Nesta pesquisa utiliza-se a documentação, com reportagens jornalísticas do jornal The New York Times - NYT publicadas no periódico no ano de 2012.

Durante o ano de 2012 houve 46 reportagens abordando o Brasil e, deste total, oito reportagens falavam sobre a Amazônia. As notícias aparecem em ordem temporal crescente, com as primeiras ocorrências datando o mês de janeiro e as últimas o mês de dezembro. As reportagens foram publicadas no site www. nytimes.com no idioma inglês nas datas $06 / 01 / 2012, \quad 14 / 01 / 2012,04 / 05 / 2012$, $06 / 05 / 2012, \quad 17 / 05 / 2012, \quad 10 / 06 / 2012$, 25/11/2012, 25/11/2012 e 16/12/2012. A coleta foi realizada em dezembro de 2012, (Quadro1) de forma quantitativa, através da palavra-chave "Amazon" e do nome do correspondente "Simon Romero" e que constassem na editoria "Americas/world". Todas as reportagens foram traduzidas pelos autores no ano de 2012.

Quadro 0 - Listagem das reportagens que serão analisadas

\begin{tabular}{|c|c|c|c|}
\hline Matéria & Data de publicação & Título da matéria & Português (tradução da autora) \\
\hline (A) & $06 / 01 / 2012$ & $\begin{array}{l}\text { Hatians take } \\
\text { arduous path to } \\
\text { Brazil, and jobs }\end{array}$ & $\begin{array}{c}\text { Haitianos pegam árdua rota para } \\
\text { chegar ao Brasil. }\end{array}$ \\
\hline (B) & $14 / 01 / 2012$ & \begin{tabular}{|c|} 
Once Hidden by \\
Forest, Carvings in \\
Land Attest to \\
Amazon's Lost \\
World \\
\end{tabular} & $\begin{array}{l}\text { Uma vez escondidas pela floresta, } \\
\text { esculturas testemunham o mundo } \\
\text { perdido da Amazônia. }\end{array}$ \\
\hline (C) & 04/05/2012 & $\begin{array}{l}\text { Brazil sending } \\
\text { more troops to } \\
\text { guard amazon } \\
\text { borders }\end{array}$ & $\begin{array}{l}\text { Brasil envia mais tropas para } \\
\text { proteger as fronteiras } \\
\text { amazônicas. }\end{array}$ \\
\hline (D) & 06/05/2012 & $\begin{array}{c}\text { Amid Brazil's Rush } \\
\text { to develop workers } \\
\text { resist }\end{array}$ & $\begin{array}{l}\text { Em meio à pressa do Brasil para } \\
\text { desenvolver, trabalhadores } \\
\text { resistem. }\end{array}$ \\
\hline (E) & $17 / 05 / 2012$ & \begin{tabular}{|c|}
$\begin{array}{c}\text { Brazil leader's } \\
\text { faces defining } \\
\text { decisions on bill } \\
\text { relaxing protection } \\
\text { of forest }\end{array}$ \\
\end{tabular} & $\begin{array}{c}\text { Líder do Brasil encara definição } \\
\text { sobre o projeto de lei de proteção } \\
\text { das florestas. }\end{array}$ \\
\hline (F) & $10 / 06 / 2012$ & $\begin{array}{c}\text { Violence Hits } \\
\text { Brazil tribes in } \\
\text { scramble for land }\end{array}$ & $\begin{array}{c}\text { Violência atinge tribos brasileiras } \\
\text { na luta por terras. }\end{array}$ \\
\hline (G) & $25 / 11 / 2012$ & $\begin{array}{c}\text { Swallowing rain } \\
\text { forest cities surge } \\
\text { in Amazon }\end{array}$ & $\begin{array}{c}\text { Cresce a população da Amazônia } \\
\text { Brasileira. }\end{array}$ \\
\hline (H) & $16 / 12 / 2012$ & $\begin{array}{c}\text { Brazil expands } \\
\text { mine drive future, } \\
\text { but cost is a } \\
\text { treasured link to } \\
\text { past }\end{array}$ & $\begin{array}{l}\text { Brasil expande minerações para } \\
\text { conduzir o futuro, mas o custo é } \\
\text { uma ligação presa ao passado. }\end{array}$ \\
\hline
\end{tabular}

Fonte: Pesquisa de Campo - Corradi, Assumpção e Brabo 2014 
Foram analisadas as oito reportagens identificadas quanto à estrutura da classificação bipolar e em enunciação com base em Bardin (1988), assim como houve a observação e sistematização de elementos de apoio (fotos, legendas, vídeo, link, hipertexto) e compilação do depoimento do jornalista Simon Romero.

\section{Fragmentos da análise}

Reportagem A - Haitianos pegam árdua rota para chegar ao Brasil, publicada em 6/01/2012.

$\mathrm{Na}$ reportagem há 21 parágrafos, um subtítulo da reportagem (olho da matéria), seis fotos com legenda, um vídeo, um hipertexto e cinco links.

\section{Quadro 0-Características da reportagem $A$}

\begin{tabular}{|c|c|c|c|c|c|c|}
\hline \multicolumn{7}{|c|}{ Matéria A-Haitianos pegam árdua rota para chegar ao Brasil } \\
\hline Parágrafos & Otho da matéria & \multicolumn{5}{c|}{ Multimídia } \\
\hline 21 & 1 & Fotos & Legenda & vídeo & hipertexto & Link \\
\hline & & 6 & 6 & 1 & 1 & 5 \\
& & & & & & \\
\hline
\end{tabular}
2014.

Fonte: Pesquisa de Campo - Corradi, Assumpção e Brabo

${ }^{3}$ Disponivel em $<$ http://www.nytimes. com/2012/01/07/world/ americas/brazils-boom-absorbs-haitis-poor-for-now.html?pagewante$d=$ all\&_r $=0>$ Acesso $\mathrm{em}$ 20 set 2013.
Após análise da classificação bipolar, encontrou-se a predominância de itens de caráter positivo na reportagem, o que equivale a $62 \%$ da reportagem. $\mathrm{Na}$ análise de enunciação, há mais parágrafos argumentativos, o que representa $76 \%$ da matéria. Percebe-se que Romero escolheu utilizar a imagem do Brasil como um país acolhedor, principalmente pela escolha das palavras utilizadas. No $10^{\circ}$ parágrafo a frase "as autoridades federais reagiram enviando toneladas de alimentos para os haitianos que atualmente somam mais de 1.000 em cada assentamento", neste período, percebe-se que o jornalista escolheu dizer que o país está auxiliando na chegada desses estrangeiros, e que o Brasil começa a lidar com um novo dilema: a entrada de imigrantes em território nacional. Romero também fala sobre o índice da taxa de desemprego, o que dificulta o número de vagas principalmente na construção civil.

O correspondente escolhe retratar a Amazônia como porta de acesso aos estrangeiros para adentrar no país, com isso ele também ressalta a vulnerabilidade das fronteiras do Brasil. Esta situação é ressaltada na fala de Francisco Joseph, que compra cartões, em Cobija, cidade boliviana, cartões que ele revende no Brasil. O jornalista também destaca que a região abriga grande partes dos haitianos, como se lê: "as autoridades estimam que cerca de 500 haitianos vivem em Porto Velho, e que cerca de 700 estão em Manaus, maior cidade da Amazônia brasileira".

Romero escolheu ressaltar nos depoimentos dos entrevistados que o Brasil é um país do futuro, já que está sendo cenário industrial, principalmente com a construção de estradas e hidrelétricas, obras que necessitam de mão-de-obra massiva. O jornalista traz também questões econômicas como a queda do índice de desemprego no país e o aumento da renda dos brasileiros pobres, "crescendo sete vezes mais do que a renda dos ricos", o que significa desenvolvimento de um Estado.

Para ilustrar a reportagem é utilizado um vídeo ${ }^{3}$ com a legenda "Haitianos encontram esperança no Brasil - Centenas de cidadãos haitianos que buscam uma vida melhor no Brasil encontram-se presos na fronteira com a Bolívia”.

A reportagem também possui seis fotos. Na primeira foto (figura 1), há a presença de haitianos jovens praticando o seu culto dentro de um ambiente improvisado, com a seguinte legenda "Hai- 
tianos candidatos a imigrantes no Brasil usam lobby do hotel como uma igreja improvisada onde eles cantam e oram em Brasiléia, Brasil. Milhares de haitianos apostaram tudo e fizeram o seu caminho para chegar a pequenas cidades da Amazônia Brasileira no ano passado em uma busca desesperada por trabalho".

Percebe-se que o fotógrafo utilizou escolher um ambiente com pouca luz para mostrar a simplicidade do Hotel Brasiléia, no pequeno município de Brasiléia, no Acre.

Figura 1 - Foto 1 da Reportagem A

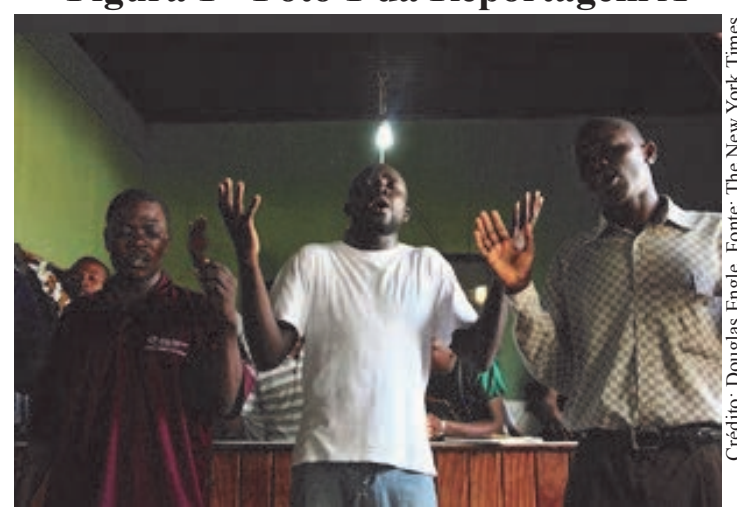

Figura 2 - Foto 2 da Reportagem A

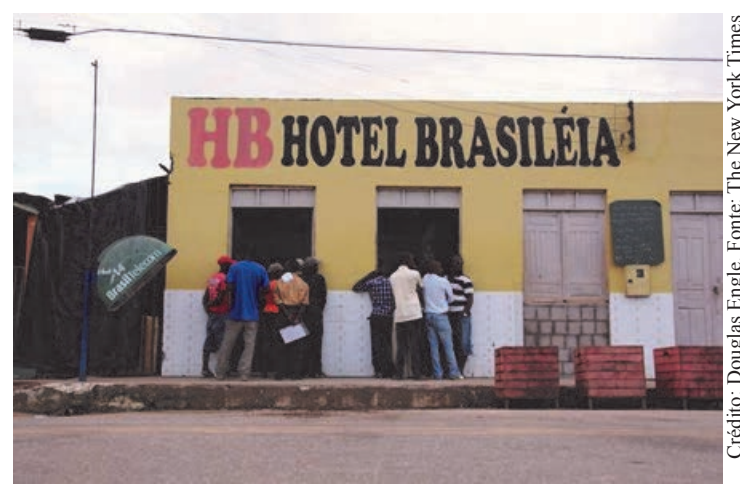

$\mathrm{Na}$ segunda foto (figura 2), a imagem mostra a frente do Hotel Brasília, localizado no município de mesmo nome sito ao sul do Acre, a $273 \mathrm{~km}$ da capital, Rio Branco. "Muitos permanecem por semanas em Brasiléia e outras cidades antes de ver concedidos vistos humanitários que lhes permite trabalhar no Brasil. Aqui, as pessoas se reuniram no Hotel Brasiléia."

A reportagem destaca a simplicidade do hotel e o exalta mais uma vez. A cor amarela da fachada do estabelecimento é associada à luz do sol, uma cor quente, suficiente para chamar atenção dos estrangeiros que chegam à região. Outra forma de direcionar o olhar para o hotel é através da escolha das fontes do nome do local: as iniciais "HB" em vermelho remetem à força, chama atenção, pois é caracterizada, na publicidade, por ser uma cor estimulante que chega mais rapidamente aos olhos dos que chegam. Os estrangeiros na imagem vestem roupas simples e fazem fila em frente ao hotel, seus olharem sugerem impaciência na espera por vaga, depois de uma longa viagem até chegar à Amazônia Brasileira.

A terceira imagem (figura 3) registra haitianos reunidos na praça do município, descansando, conversando, e muitos possuem expressões de tranquilidade confirmadas pelo texto da reportagem: "Cerca de 4 mil haitianos imigraram para o Brasil desde o terremoto de 2010. O Brasil fez uma exceção para os haitianos, em contraste com os candidatos a emprego de países como Paquistão, Índia e Bangladesh, que chegam através de rotas amazônicas similares, mas são normalmente expulsos. Aqui, os haitianos se reúnem na praça principal”. Ali registra-se a presença de haitianos em momento de

Figura 3 - Foto 3 da Reportagem A

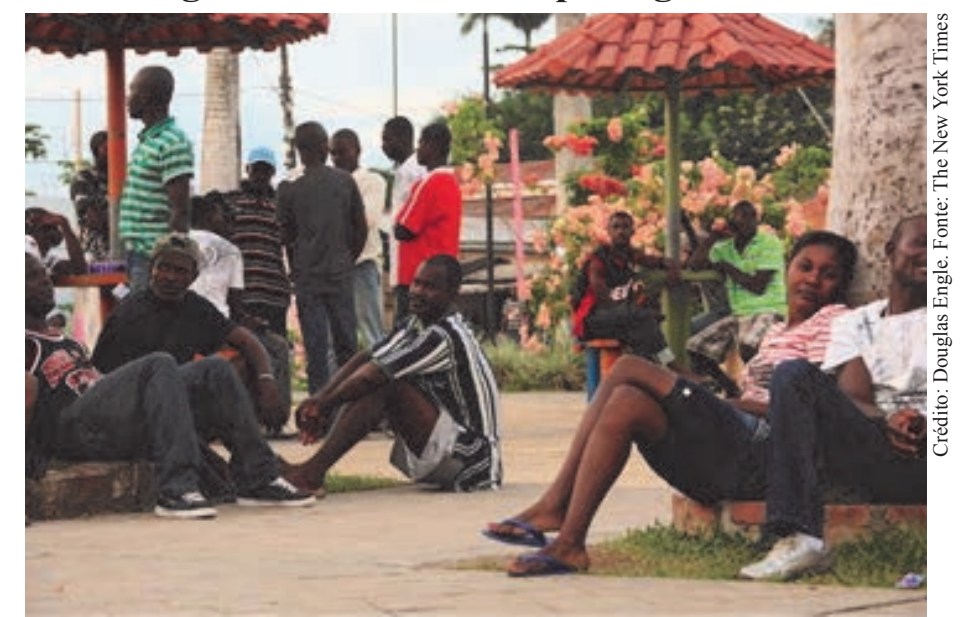


lazer, conversando em uma praça da cidade.

$\mathrm{Na}$ quarta foto (figura 4), encontram-se duas pessoas dormindo em um corredor de uma casa, sem camas e com roupas e malas espalhadas no chão. "Muitos dormem em quartos apertados do hotel, que funciona como um abrigo e igreja." O fotógrafo

Figura 4 - Foto 4 da Reportagem A

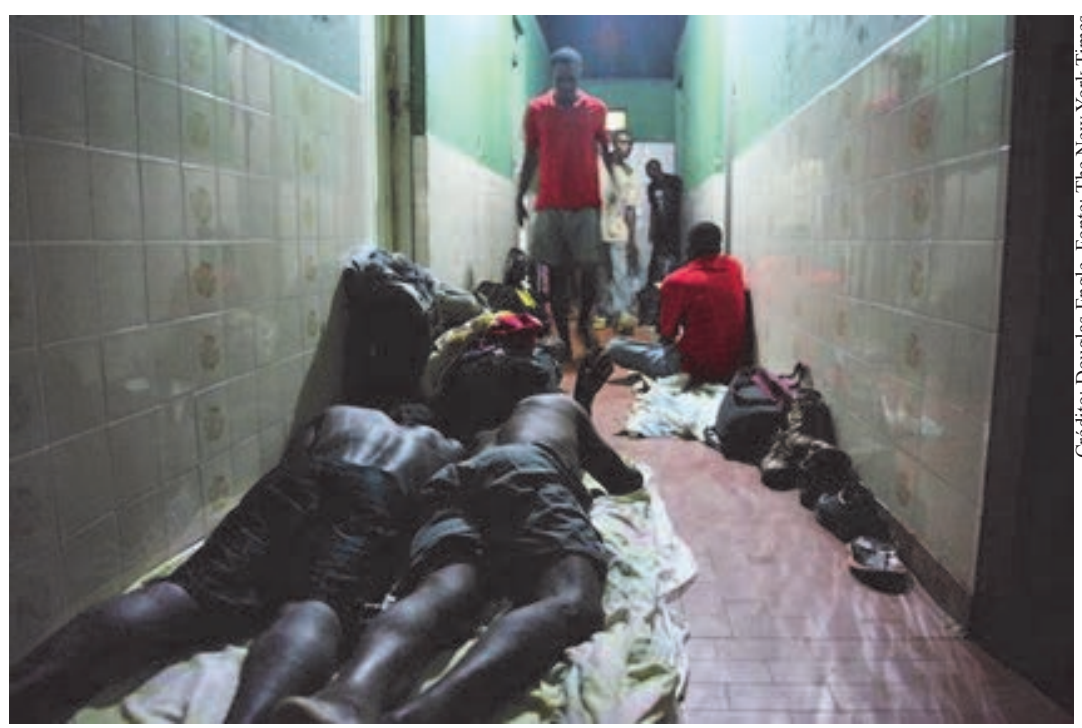

Figura 5 - Foto 5 da Reportagem A

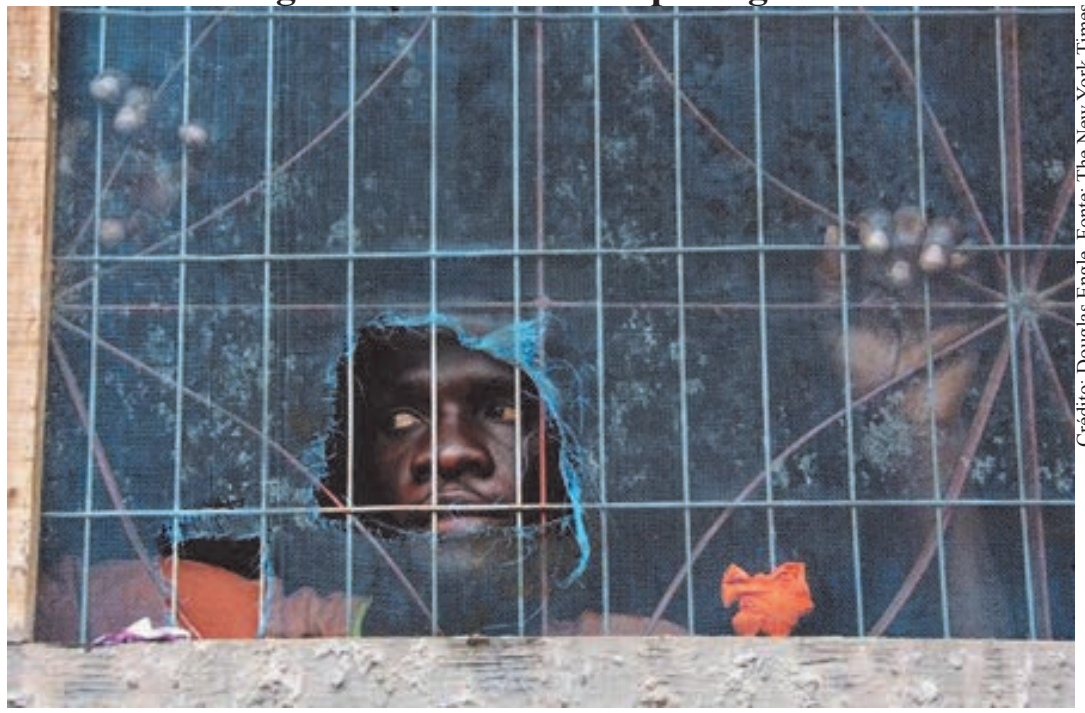

veu enquadrar as duas pessoas deitadas no chão para representar a falta de espaço e de auxílio do governo federal na manutenção dos estrangeiros. Percebe-se também amontoados de roupas, sapatos e utensílios pessoais jogados no chão, o que remete ao desconforto e à falta de qualidade de vida em que eles se encontram.

A quinta foto (figura 5), usada na reportagem, mostra a imagem de um haitiano em uma janela com grades, sua expressão remete à tristeza e ao desolamento e o texto reforça a relação de isolamento: "Um imigrante em uma janela de hotel. Lidar com uma crise de imigração em sua fronteira é um novo dilema para o Brasil, que até recentemente estava mais preocupado com a saída de seus próprios cidadãos em busca de oportunidades nos países ricos e industrializados do que responder à chegada de milhares de estrangeiros pobres."

$\mathrm{Na}$ última foto (figura 6), há uma imagem de um imigrante sentado em frente ao Hotel Brasiléia, enquanto o dia termina. A escolha da cor da foto com o tom marrom relaciona-se com a cor da lama, com sensações de desconforto, de pesar. O homem, personagem, é magro, de estatura mediana, e olha para o lado, como se esperasse algo ou alguém. Reforçando essa expectativa no texto da reportagem: "Desde 2004, o Brasil enviou tropas para liderar uma missão de paz das Nações Unidas no Haiti. Mas agora existem mais haitianos no Brasil do que soldados brasileiros no Haiti. A maioria dos haitianos espera passar algumas semanas no limbo da imigração de Brasiléia, antes de seguir em frente".

$\mathrm{Na}$ reportagem A destacam-se hiperlinks nas seguintes palavras: Haiti, Imigração, Crescendo sete vezes mais, Hidrelétrica e Missão de paz, enquanto nos hipertextos há apenas um gráfico, onde mostra a localização da cidade de Brasiléia, no Estado do Acre.

\section{Resultados}

De acordo com a classificação Bipolar (positiva e negativa) e enunciativa (ar- 
gumentativa e crítica) de Bardin (1988), verificou-se a visão geral das reportagens e as suas características específicas de cada parágrafo. No geral, as reportagens tiveram caráter positivo e argumentativo (quadro 4).

Percebeu-se também uma maior incidência de reportagens sobre a região amazônica no mês de maio, visto que foi o mês em que a presidente do Brasil, Dilma Rousseff, vetou o código florestal. Duas reportagens no mesmo mês fazem menção às hidrelétricas em seus hiperlinks.

Verificou-se que assuntos sobre o meio ambiente foram destaque nas publicações consultadas, especialmente questões que envolveram temas como confrontos agrários, mineração, migração, arqueologia e construção/funcionamento de usinas hidrelétricas. Dentro da amostra de oito reportagens, duas são referentes à arqueologia.

Verificou-se que o jornalista, correspondente internacional, tem conhecimento da importância da região amazônica

\section{Quadro 4 - Lista dos aspectos gerais e específicos de cada matéria}

\begin{tabular}{|c|c|c|c|c|}
\hline \multicolumn{2}{|c|}{ Reportagem } & Visão Geral & Específico & Tradução/site/autora \\
\hline (A) & $\begin{array}{l}\text { Haitians Take } \\
\text { Arduous Path to } \\
\text { Brazil, and Jobs }\end{array}$ & Positivo & Argumentativo & $\begin{array}{c}\text { Haitianos pegam } \\
\text { ardua rota para chegar } \\
\text { ao Brasil }\end{array}$ \\
\hline (B) & $\begin{array}{c}\text { Once Hidden by } \\
\text { Forest, Carvings } \\
\text { in Land Attest to } \\
\text { Amazon's Lost } \\
\text { World }\end{array}$ & Positivo & Crítico & $\begin{array}{l}\text { Uma vez escondidas } \\
\text { pela floresta, esculturas } \\
\text { testemunham o mundo } \\
\text { perdido da Amazônia. }\end{array}$ \\
\hline (C) & $\begin{array}{l}\text { Brazil Sen ding } \\
\text { More Troops to } \\
\text { Guard Amazon } \\
\text { Borders }\end{array}$ & Positivo & $\begin{array}{c}\text { Argumentativo e } \\
\text { Crítico }\end{array}$ & $\begin{array}{c}\text { Brasil envia mais } \\
\text { soldados para proteger } \\
\text { as fronteiras } \\
\text { Amazônicas. }\end{array}$ \\
\hline (D) & $\begin{array}{l}\text { Amid Brazil's } \\
\text { Rush to Develop, } \\
\text { Workers Resist }\end{array}$ & Positivo & Crítico & $\begin{array}{c}\text { Em meio à pressa do } \\
\text { Brasil para } \\
\text { desenvolver, } \\
\text { trabathadores resistem. }\end{array}$ \\
\hline (E) & $\begin{array}{l}\text { Brazil's Leader } \\
\text { Faces Defining } \\
\text { Decision on Bill } \\
\text { Relaxing } \\
\text { Protection of } \\
\text { Forests }\end{array}$ & Positivo & Argumentativo & $\begin{array}{l}\text { Lider do Brasil encara } \\
\text { definição sobre } \\
\text { projeto de lei de } \\
\text { Proteção das florestas }\end{array}$ \\
\hline (F) & $\begin{array}{c}\text { Violence Hits } \\
\text { Brazil Tribes in } \\
\text { Scramble for Land }\end{array}$ & Negativa & Argumentativo & $\begin{array}{c}\text { Violência atinge tribos } \\
\text { brasileiras na luta por } \\
\text { terras }\end{array}$ \\
\hline (G) & $\begin{array}{l}\text { Swallowing Rain } \\
\text { Forest, Cities } \\
\text { Surge in Amazon }\end{array}$ & Positiva & Argumentativo & $\begin{array}{l}\text { Cresce a população da } \\
\text { Amazônia brasileira }\end{array}$ \\
\hline (H) & $\begin{array}{l}\text { Brazil Expands } \\
\text { Mines to Drive } \\
\text { Future, but Cost Is } \\
\text { a Treasured Link } \\
\text { to Its Past }\end{array}$ & Positivo & Argumentativa & $\begin{array}{c}\text { Brasil expande } \\
\text { mineração para } \\
\text { conduzir o futuro, mas } \\
\text { o custo é uma ligação } \\
\text { presa ao passado. }\end{array}$ \\
\hline
\end{tabular}

Fonte: Corradi, Assumpção e Brabo 2014 
para o mundo. Tanto isto é fato que quando questionado sobre as reportagens que pretende fazer no Brasil, ele ressalta que gostaria de compreender melhor o Estado do Pará e seus problemas econômicos e sociais. Percebeu-se tanto em seu discurso, quanto dos outros correspondentes, que a região atrai a mídia internacional, visto que os demais correspondentes in-

\section{№ de reportagens por mês}

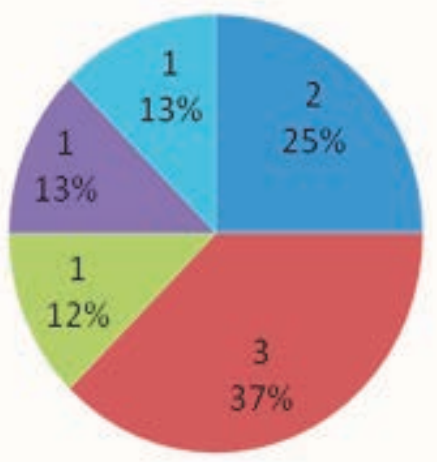

ejaneiro

Emaio

Ejunho

Enovembro

- dezembro

Fonte: Site do The New York Times. Elaboração Corradi, Assumpção e Brabo 2014

ternacionais escolheriam a Amazônia para fazer suas próximas reportagens.

Percebe-se também que os valores-notícias da região permitiram que o correspondente Simon Romero elencassem temas que relatam as grandes dificuldades da região.

\section{Assuntos Frequentes}

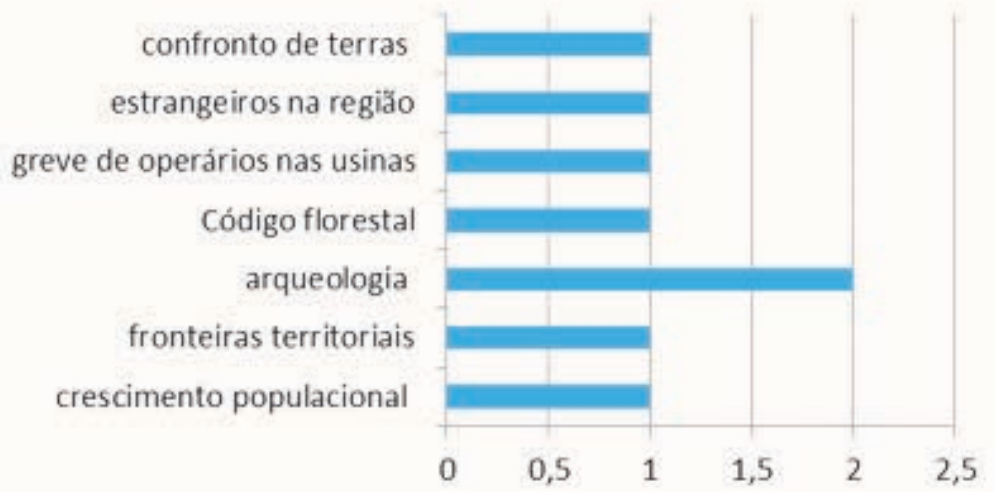

Fonte: Site do The New York Times. Elaboração Corradi, Assumpção e Brabo 2014

\section{Considerações finais}

Essa pesquisa destacou em seu desenvolvimento os seguintes pontos: quanto as formas de tratamento da região amazônica, as reportagens têm, na sua totalidade, maior incidência de aspectos argumentativos e positivos. No entanto, percebe-se que o jornalista, mesmo citando alguns dados históricos e de pesquisas em seus textos, não faz contextualização histórica aprofundada dos problemas regionais. Para embasar suas reportagens, ele centraliza seus posicionamentos nos argumentos dos personagens.

Outra questão destacada são os assuntos debatidos, os quais giram em torno de conflitos, contraste econômico, mineração, hidrelétricas, bem como a beleza exótica da região. Durante a pesquisa percebeu-se a ausência de outros assuntos que envolvem a região amazônica, tais como reportagens culturais, biodiversidade, saúde e desenvolvimento sustentável. Assim chega-se à conclusão de que os valores-notícias adotados pelo periódico direcionam a região amazônica como espaço de disparidades e que essas dificuldades abrangem os temas retratados no periódico.

Estruturalmente as reportagens destacadas sobre a região utilizaram-se de fotos. As fotos escolhidas para ilustrar as reportagens também ressaltam as ideias de seu conteúdo, visto que predominam imagens de florestas, indígenas, hidrelétricas, casas precárias, vestígios arqueológicos. Fotos destacadas com o conjunto de imagem e inter-relação com luz e sombra, reforçando a disparidade na representação simbólica presente e marcada entre o texto e as imagens em cada reportagem. Quanto mais polêmicas as matérias, mais há recurso de uso de fotos. Assim como a 
quantidade de links e hiperlinks.

De modo geral as reportagens e seus recursos repassam a ideia da Amazônia como espaço de conflitos e disparidades.

Outro aspecto observado está relacionado com ausência de escritórios de grande empresa jornalística e a presença de correspondentes estrangeiros na região, o que limita o número de reportagens, visto que o custo de manter um profissional fora de seu país é um gasto para os veículos de comunicação. É necessário compreender a importância do papel do jornalista internacional, das editorias internacionais, visto que cada vez mais a sociedade está globalizada e a contextualização de notícias e fatos é de grande valor para a humanidade.

No caso, destaca-se que o jornalista em questão, Simon Romero, viveu muitos anos no Brasil e em outras regiões da América Latina, o que o faz próximo aos assuntos e suas características específi- cas. Neste papel, o jornalista em sua produção de notícias deve estar apto a selecionar os fatos e a concentrar sua atenção ao público, de forma que traga significados e promova a solução de uma denúncia ou problema exposto na reportagem.

$\mathrm{E}$, finalmente, há que se afirmar que atuar na Amazônia implica, pelo valor da notícia, ter sempre assunto a explorar, já que a região é de interesse mundial e assim se faz necessário expor as suas carências em políticas sociais e políticas culturais. A Amazônia é vista nas reportagens como um espaço isolado, portanto deve ser retratada como um espaço muito mais complexo do que uma área composta de rios, matas e animais, e sim que envolve também uma população formada por diversas raças e tipos de pessoas. Logo, é essencial que a comunidade internacional reflita a discussão dos seus problemas para conhecê-la e preservá-la.

\section{Referências bibliográficas}

AVIGHI, Carlos Marcos. "A globalização e o jornalismo internacional nos periódicos brasileiros." In: Caligrama - Revista de Estudos e Pesquisa e mídia, n 3, SET-DEZ de 2007. Disponível em HTTP://www.eca.usp.br/caligrana/n_9/pdf/02_avighi. pdf . Acessado em 12 ago 2013.

NATALI, João Batista. Jornalismo Internacional. São Paulo: Contexto, 2004.

NEXTEL, Mateus. "Editor acredita em crescimento do jornalismo internacional." In: Observatório da Imprensa, 15 de outubro de 2013. Disponível em http:// observatoriodaimprensa.com.br/news/view/_ed768_editor_acredita_em_crescimento_do_jornalismo_internacional. Acesso em 15 out 2013.

ROMANCINI, RICHARD; LAGO, CLÁUDIA. História do Jornalismo no Brasil. Florianópolis: Insular, 2007.

Estudos em Jornalismo e Mídia está sob a licença Creative Commons 2.5 